\title{
Systematic Review \\ Biomolecule-Mediated Therapeutics of the Dentin-Pulp Complex: A Systematic Review
}

\author{
Foteini Machla ${ }^{1}\left(\mathbb{D}\right.$, Ioannis Angelopoulos $^{2}$, Matthias Epple ${ }^{3}{ }^{\circledR}$, Maria Chatzinikolaidou ${ }^{4,5}(\mathbb{D}$ \\ and Athina Bakopoulou 1,*
}

1 Department of Prosthodontics, School of Dentistry, Faculty of Health Sciences, Aristotle University of Thessaloniki (A.U.Th), 54124 Thessaloniki, Greece; fcmachla@dent.auth.gr

2 School of Dentistry, Faculty of Health Sciences, Aristotle University of Thessaloniki (A.U.Th), 54124 Thessaloniki, Greece; iangelopoulos84@gmail.com

3 Inorganic Chemistry and Center for Nanointegration Duisburg-Essen (CeNIDE), University of Duisburg-Essen, 45117 Essen, Germany; matthias.epple@uni-due.de

4 Department of Materials Science and Technology, University of Crete, 70013 Heraklion, Greece; mchatzin@materials.uoc.gr

5 Institute of Electronic Structure and Laser, Foundation for Research and Technology-Hellas, 70013 Heraklion, Greece

* Correspondence: abakopoulou@dent.auth.gr; Tel.: +30-2310-999540

check for updates

Citation: Machla, F.; Angelopoulos, I.; Epple, M.; Chatzinikolaidou, M.; Bakopoulou, A. BiomoleculeMediated Therapeutics of the Dentin-Pulp Complex: A Systematic Review. Biomolecules 2022, 12, 285. https://doi.org/10.3390/biom12020285 Academic Editor: Bahman Anvari

Received: 31 December 2021

Accepted: 3 February 2022

Published: 9 February 2022

Publisher's Note: MDPI stays neutral with regard to jurisdictional claims in published maps and institutional affiliations.

Copyright: () 2022 by the authors. Licensee MDPI, Basel, Switzerland. This article is an open access article distributed under the terms and conditions of the Creative Commons Attribution (CC BY) license (https:// creativecommons.org/licenses/by/ $4.0 /)$.

\begin{abstract}
The aim of this systematic review was to evaluate the application of potential therapeutic signaling molecules on complete dentin-pulp complex and pulp tissue regeneration in orthotopic and ectopic animal studies. A search strategy was performed according to the Preferred Reporting Items for Systematic Reviews and Meta-Analyses (PRISMA) statement in the MEDLINE/PubMed database. Animal studies evaluating the application of signaling molecules to pulpectomized teeth for pulp tissue or dentin-pulp complex regeneration were included. From 2530 identified records, 18 fulfilled the eligibility criteria and were subjected to detailed qualitative analysis. Among the applied molecules, basic fibroblast growth factor, vascular endothelial growth factor, bone morphogenetic factor-7, nerve growth factor, and platelet-derived growth factor were the most frequently studied. The clinical, radiographical and histological outcome measures included healing of periapical lesions, root development, and apical closure, cellular recolonization of the pulp space, ingrowth of pulp-like connective tissue (vascularization and innervation), mineralized dentin-like tissue formation along the internal dentin walls, and odontoblast-like cells in contact with the internal dentin walls. The results indicate that signaling molecules play an important role in dentin/pulp regeneration. However, further studies are needed to determine a more specific subset combination of molecules to achieve greater efficiency towards the desired tissue engineering applications.
\end{abstract}

Keywords: dentin-pulp complex regeneration; signaling molecules; cell homing; tissue engineering

\section{Introduction}

According to the General Assembly of the United Nations in September 2011, oral diseases are recognized as a major health burden for many countries. During this meeting, a consensus was reached to include oral diseases in the common response to NonCommunicable Diseases (NCDs), as they share several common risk factors [1]. Dental diseases, as part of the oral disease family, are not life-threatening and are mostly preventable. However, their therapeutic management is a global health priority issue due to their very high prevalence. More specifically, 3.5 billion cases (45\% of the general population) suffer from various oral conditions, such as caries, periodontal disease, edentulism, or other oral diseases (e.g., oral cancer, myalgia, genetic diseases). Moreover, 2.3 billion cases $(29 \%)$ have untreated caries in permanent teeth [2]. Considering the constant aging of the population in high/middle income countries, the prevalence of dental diseases is expected 
to increase even more. It has also been found that oral conditions, especially dental caries, negatively impact the Health-Related Quality of Life in adults (HRQoL) [3]. It is estimated that the worldwide costs attributed to dental diseases were USD 544.41 billion in 2015, of which $12 \%$ were due to untreated dental caries [4].

Nowadays, conservative dentistry primarily uses various biomaterials to replace the diseased/defected dental tissues. Nevertheless, replacing a tissue by inert biomaterials is associated with many disadvantages, such as deterioration of the material over time in terms of its aesthetical and mechanical properties, loss of functionality, and loss of sensation of the restored tooth [5]. Therefore, research interest has recently targeted regenerative and tissue engineering-based treatment approaches.

The structure of the tooth is unique compared to other parts of the human body. Externally, teeth consist of hard tissues, i.e., enamel that covers the tooth crown, cementum that covers the root, and dentin that lies underneath these two. Dentin surrounds the internal cavity of the tooth, which contains the soft pulp tissue [6]. Dentin is a bone-like tissue occupying the biggest part of the tooth volume, and has a specific microstructure, where dentinal tubules connect the pulp to the outer shell [6]. Pulp is a connective tissue consisting of nerves and vessels connected to the circulatory system by the apical foramen. The outer pulp zone constitutes a monolayer of odontoblasts, specialized cells for the sensation of the teeth. Odontoblasts consist of a cell body that is attached to the inner dentin wall and their processes run through the dentinal tubules [7]. Brannstrom's hydrodynamic theory suggests that dentinal and pulpal nerve endings are stimulated by the rapid movement of the liquid inside the dentinal tubules caused by thermal, chemical, and microbial stimuli [8]. The spatial restrain of the pulp plays a significant role in dental pathoses, because even when a mild damaging stimulus reaches the pulp, it causes inflammation, and the inability of the pulp's expansion often leads to its necrosis. In general, dental tissues do not possess regenerative properties, aside from the limited ability of the dentin-pulp complex, which results in the development of secondary dentin formation externally of the pulp.

In the past few decades, many innovations have been reported regarding the regeneration of various tissues and organs including oral and dental tissues. Tissue engineering (TE) is a promising innovative approach that utilizes the triad of stem cells (SCs), scaffolds, and stimulating factors, aiming at the regeneration of diseased, damaged, or lost tissues and organs [9]. Various dental tissue-derived mesenchymal stem cells (MSCs) have been discovered and studied, e.g., dental pulp SCs from permanent (DPSCs) teeth or deciduous (SHED) teeth, SCs from the apical papilla (SCAP), periodontal ligament SCs (PDLSCs), and orofacial bone marrow MSCs (BMMSCs) [10]. In addition to this, dental SCs are being investigated for the regeneration of non-dental tissues [11]. Stem cells can be transplanted to the desired area (cell-based approach) or the already-existing endogenous host's SCs can be activated through signaling, recruited, and differentiated into relevant cell types (so-called cell-homing approach). Dental research has only recently navigated towards cell-free approaches, mainly to avoid the ethical and legal limitations of the cell-based option that arise from the potential risk of immunogenic reaction and tumorigenesis [12]. A large variety of scaffolds have already been evaluated in dental tissue engineering. These scaffolds should be biocompatible, biodegradable, and promote cell proliferation and differentiation. Synthetic, natural, and smart biomaterials have been manufactured and tested, revealing promising results [13].

Stem cell differentiation is affected by intrinsic stimuli in which the transcription factors are expressed by cells, and by extrinsic stimuli with the mechanical and chemical signals provided by the extracellular matrix, growth factors, and neighboring cells [14]. The study of the stages of odontogenesis has revealed the major role of signaling molecules on stem cell fate. Many signaling molecules have been recorded and their role in dental regeneration is partially clarified [15]. Among others, growth factors (GF) such as fibroblast GF-2 (FGF2), platelet-derived GF (PDGF), and vascular endothelial GF (VEGF), are related to angiogenesis; nerve GF (NGF) to neuronal growth; transforming GF-b1 (TGFb1), stromal cell-derived factor-1 (SDF1), FGF2, and PDGF to chemotaxis; Bone Morphogenetic Protein- 
2, -4, -7, and -11 (BMP-2, -4, -7, -11), insulin-like GF (IGF), TGFb1, PDGF, FGF2, and NGF to differentiation; and PDGF, FGF2, IGF, VEGF, TGFb1, and SDF1 to proliferation [16]. Most of the above-mentioned signaling molecules are fossilized in dentin tissue. Therefore, suggestions on using chelating agents, e.g., EDTA, to release these molecules from the dentin tissue have been described in the literature, leading to a successful release and treatment outcome [17].

This systematic review based on animal studies elucidates the efficacy of signaling molecules in combination with or without scaffolds, on the cell-free regeneration of the pulp tissue or of the entire dentin-pulp complex.

\section{Materials and Methods}

This systematic review was reported following the Preferred Reporting Items for Systematic Reviews and Meta-Analyses (PRISMA) statement [18]. Based on the PICO principle (Population, Intervention, Comparison, and Outcome), the following review question was formulated: Does the therapeutic application of biomolecules assist dentin/pulp regeneration through cell homing?

\subsection{Search Strategy}

Two independent reviewers performed the literature search in the MEDLINE database through PubMed search engine. In case of disagreement, a consensus between the two reviewers was reached after thorough analysis of the data. The search was performed until November 2021, without any other limit set for the publication date. The search strategy is presented in Table 1.

Table 1. Terms for database search strategy.

PubMed Search Strategy

((dentin) OR (pulp) OR (tooth)) AND ((regeneration) OR (tissue engineering)) AND

((biomolecules) OR (growth factors) OR (signaling molecules))

\subsection{Study Selection}

Studies that were stated as retracted, and reviews or studies that were written in any other language than English, were not screened. Two authors screened the titles and abstracts of the retrieved articles independently and the full texts of the potentially eligible studies were assessed. The eligibility criteria addressed original papers of animal studies in the English language that evaluated signaling molecules in the dentin-pulp complex or pulp tissue complete regeneration via cell homing. The identification of the included articles was not limited by the presence or absence of scaffolds/carriers/delivery systems, the type of signaling molecules, or the application in ectopic/orthotopic animal models. In vitro studies were excluded from this systematic review. In vivo studies that evaluated dentin/pulp regeneration through cell-based (i.e., cell transplantation) techniques were excluded, even if biomolecules were applied. Studies on partial regeneration (pulp capping or partial pulpotomy) were excluded. Review articles, editorial letters, short communications, case reports, and case series were also excluded.

\subsection{Data Extraction}

The following data were retrieved from all included studies: author; study model (orthotopic, ectopic); animal and replicate number; tooth information; biomolecules applied and their concentration; restorative material; treatment duration; evaluation methodology; and main results.

\subsection{Risk of Bias}

The evaluation of risk of bias of the included studies was based on the SYRCLE's tool for animal studies, developed by the Systematic Review Centre for Laboratory Animal 
Experimentation [19]. The following parameters were considered: random sequence generation (selection bias); baseline characteristics (selection bias); blinding of outcome assessment (detection bias); incomplete outcome data (attrition bias); selective reporting (reporting bias); and other bias (design-specific risks). Each component was classified as low, unclear, or high risk of bias.

\section{Results}

\subsection{Study Selection}

The PRISMA flow diagram depicting the path of information through the different phases of the systematic review is shown in Figure 1. A total of 2530 records were identified, 507 of which were not screened (retracted articles, reviews, non-English texts, non-available abstracts). Out of the 2023 potentially relevant articles that were screened, 1934 were excluded based on the eligibility criteria. Full texts of 89 studies were assessed, 71 of which were excluded due to the following exclusion criteria: partial pulp regeneration studies (pulp capping and partial pulpotomy) $(n=51)$; cell transplantation studies $(n=12)$; and studies in humans $(n=8)$.

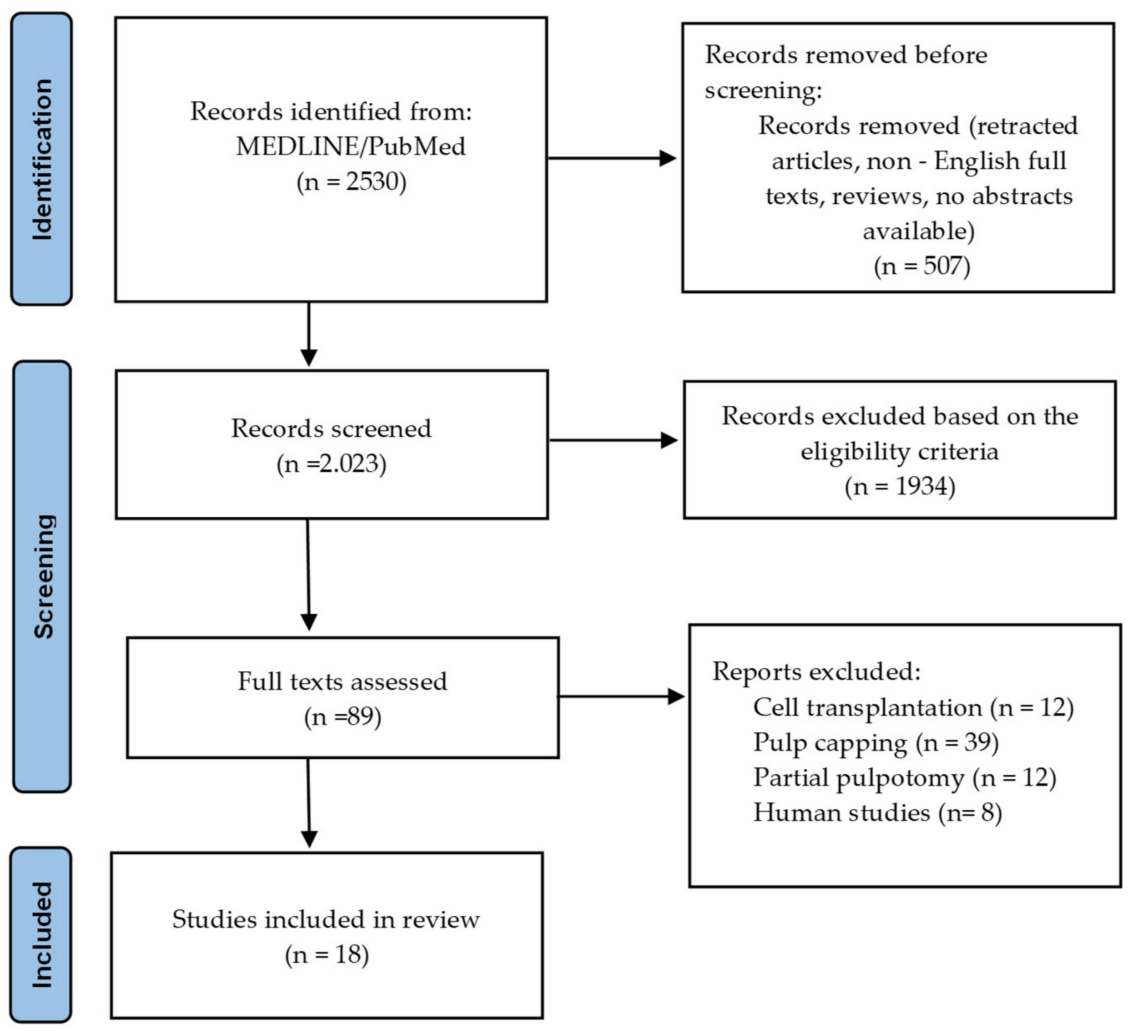

Figure 1. PRISMA flow diagram.

\subsection{Descriptive Analysis}

Out of the 18 included studies on complete dentin-pulp complex or pulp tissue regeneration, 10 used an orthotopic model (teeth of the animal were treated), while 8 used an ectopic model (allogenic teeth were extracted, treated, and transplanted subcutaneously in another animal). The information collected from the orthotopic and ectopic studies included in this systematic review can be seen in Tables 2 and 3, respectively. The most frequently used animal type in orthotopic studies was dogs (70\%), while ferrets, minipigs and rats were used in the rest of the studies. In the ectopic model, 75\% of the studies were performed on mice and the rest on rats. The transplanted teeth originated from humans $(87.5 \%)$, with only one study involving porcine teeth. The age, sex, and weight of the animals were the most frequently stated animal characteristics. 
Table 2. Orthotopic animal studies *. The studied signaling biomolecules are indicated in bold.

\begin{tabular}{|c|c|c|c|c|c|c|}
\hline Author & $\begin{array}{c}\text { Animal/ } \\
\text { Sample Size }\end{array}$ & $\begin{array}{l}\text { Tooth Type/ } \\
\text { Pulp State }\end{array}$ & $\begin{array}{l}\text { Chemomechanical Canal } \\
\text { Preparation }\end{array}$ & $\begin{array}{l}\text { Signaling Molecules, Groups/ } \\
\text { Concentrations/ } \\
\text { Restorative Material/ } \\
\text { Duration of Treatment } \\
\end{array}$ & $\begin{array}{l}\text { Evaluation } \\
\text { Methodology }\end{array}$ & Main Results \\
\hline $\mathrm{Xu}[20]$ & $\begin{array}{l}\text { Beagle dogs } \\
\text { (5 months old) } \\
3 \text { dogs, } 36 \text { teeth } \\
\text { (12 teeth/group) }\end{array}$ & $\begin{array}{l}\text { Single-rooted immature } \\
\text { anterior teeth } \\
\text { Healthy pulp }\end{array}$ & $\begin{array}{l}1.25 \% \mathrm{NaOCl}, 17 \% \mathrm{EDTA}, \\
\text { sterile distilled water }\end{array}$ & $\begin{array}{ll}\text { - } & \text { (A) CGF (B) untouched teeth (C) } \\
\text { only pulpectomized teeth } \\
\text { - } \quad 2 \mathrm{~mm}^{3} \text { CGF fragments } \\
\text { B P plus + GIC } \\
8 \text { weeks }\end{array}$ & $\begin{array}{l}\text { Radiographs } \\
\text { Histology } \\
\text { (HE, MT) } \\
\text { IHC (VEGF, Nestin) }\end{array}$ & $\begin{array}{l}\text { Immature teeth continued to develop } \\
\text { as in group B (ingrowth of soft tissues } \\
\text { in the root canal, thickened internal } \\
\text { root dentin walls, closed apex) } \\
\text { Regenerated pulp-like tissue, } \\
\text { vascularization, and innervation } \\
\text { (moderate expression of VEGF } \\
\text { and Nestin) }\end{array}$ \\
\hline Yang [21] & $\begin{array}{c}\text { Beagle dogs } \\
\text { (12 months old, female) } \\
2 \text { dogs, } 8 \text { teeth, } 16 \text { roots } \\
\text { (8 roots per group) }\end{array}$ & $\begin{array}{l}\text { Mature, closed-apex } 2 \mathrm{nd} \text { and } \\
\text { 3rd lower premolars } \\
\text { Apical periodontitis induction } \\
\text { for } 90 \text { days }\end{array}$ & $\begin{array}{l}\text { (1) Widening of apical } \\
\text { foramen up to \#80 K-file, } \\
2.5 \% \text { NaOCl, } 17 \% \text { EDTA, } \\
\text { sterile saline, TAP, } \\
\text { intermediate restorative } \\
\text { material and GIC for } 4 \\
\text { weeks } \\
\text { (2) } 2.5 \% \text { NaOCl, sterile } \\
\text { saline, and treatment }\end{array}$ & $\begin{array}{l}\text { (A) SDF-1a on silk fibroin } \\
\text { scaffolds with evoked bleeding } \\
\text { (B) only evoked bleeding (C) } \\
\text { untouched teeth } \\
\text { 100 ng SDF-1a in } 1.5-2 \mathrm{~mm}^{3} \text { silk } \\
\text { fibroin scaffolds } \\
\text { - } \quad \text { MTA + composite resin } \\
\text { - } 3 \text { months }\end{array}$ & $\begin{array}{l}\text { Histology (HE, MT, or } \\
\text { picrosirious red) } \\
\text { IHC (CD31, PCNA, h-mit, Atg5, } \\
\text { LC3) } \\
\text { IF (DSP, CD31, LC3, h-mit) } \\
\text { TEM, Protein extraction, } \\
\text { Western blot analysis }\end{array}$ & $\begin{array}{l}\text { - A: primarily, regenerated connective } \\
\text { tissue (rCT) of low to moderate density } \\
\text { with low to moderate number of blood } \\
\text { vessels, thin layer of raw regenerated } \\
\text { mineralized tissue (rMT) along the } \\
\text { dentinal walls, fibrous matrix similar to } \\
\text { normal pulp, higher number of Atg5 or } \\
\text { LC3 positive cells compared to N.C. } \\
\text { B: Extensive rMT along dentinal walls } \\
\text { and in the middle of the canal, rCT } \\
\text { with few blood vessels } \\
\text { Little nerve bundles in A and B groups }\end{array}$ \\
\hline Alqahtani [23] & $\begin{array}{c}\text { Beagle dogs } \\
\text { (13 months old, female) } \\
2 \text { dogs, } 8 \text { teeth } \\
\text { (4-6 roots per group) }\end{array}$ & $\begin{array}{l}\text { Mature molars and premolars } \\
\text { Healthy pulp }\end{array}$ & $\begin{array}{l}\text { Widening to } 0.5 \mathrm{~mm} \text { of } \\
\text { apical foramen, } 0.5 \% \\
\text { NaOCl, } 17 \% \text { EDTA, } \\
\text { evoked bleeding }\end{array}$ & $\begin{array}{ll}\text { - } & \text { (A) porcine DP-ECM (shown to } \\
\text { contain Col1, DSP, DMP1, and } \\
\text { vWF by IF, and VEGF, and } \\
\text { TGF-b1 by ELISA) (B) collagen } \\
\text { scaffold (C) only evoked } \\
\text { bleeding } \\
\text { - } 100 \mathrm{mg} \text { DP-ECM/root canal } \\
\text { MTA + GIC } \\
\text { - } 8 \text { weeks }\end{array}$ & $\begin{array}{c}\text { Histology } \\
\text { (Goldner's trichrome) } \\
\text { IHC (CD31, DSP) }\end{array}$ & $\begin{array}{ll}\text { - } & \text { A: pulp-like formation, vascularization } \\
\text { (CD31 } & \text { and DSP } \mathrm{D}^{+} \text {cells of canine origin) } \\
\text { - } & \text { All three groups: cellular infiltration, } \\
\text { and intracanal mineralization }\end{array}$ \\
\hline
\end{tabular}


Table 2. Cont.

\begin{tabular}{|c|c|c|c|c|c|c|}
\hline Author & $\begin{array}{c}\text { Animal/ } \\
\text { Sample Size }\end{array}$ & $\begin{array}{l}\text { Tooth Type/ } \\
\text { Pulp State }\end{array}$ & $\begin{array}{c}\text { Chemomechanical Canal } \\
\text { Preparation }\end{array}$ & $\begin{array}{l}\text { Signaling Molecules, Groups/ } \\
\text { Concentrations/ } \\
\text { Restorative Material/ } \\
\text { Duration of Treatment }\end{array}$ & $\begin{array}{l}\text { Evaluation } \\
\text { Methodology }\end{array}$ & Main Results \\
\hline Ghoddusi [24] & $\begin{array}{l}\text { Mongrel dogs } \\
\text { (6 months old) } \\
3 \text { dogs, } 44 \text { teeth }\end{array}$ & $\begin{array}{l}\text { Immature premolars } \\
\text { Induced pulpitis for } 2 \text { weeks }\end{array}$ & $\begin{array}{l}\text { (1) } 5.25 \% \mathrm{NaOCl} \text {, normal } \\
\text { saline, TAP, temporary } \\
\text { filling for } 4 \text { weeks } \\
\text { (2) } 5.25 \% \text { NaOCl, normal } \\
\text { saline, evoked bleeding }\end{array}$ & $\begin{array}{ll}\text { - } & \text { (A) autologous PRP (B) MTA } \\
& \text { control (C) parafilm } \\
\text { - } & \text { PRP from } 1 \mathrm{~mL} \\
& \text { autologous blood } \\
\text { - } & \text { MTA + GIC } \\
- & 3 \text { months }\end{array}$ & $\begin{array}{l}\text { Radiographs } \\
\text { Histology (HE) }\end{array}$ & $\begin{array}{l}\text { A and B: regenerated soft connective } \\
\text { tissue and vessels, mineralized tissue } \\
\text { (cementum, PDL, and bone-like } \\
\text { tissues). No normal pulp, nerve, and } \\
\text { dentin-like tissues observed } \\
\text { - C: no regeneration observed }\end{array}$ \\
\hline Moreira [25] & $\begin{array}{c}\text { Wistar rats } \\
\text { (13 weeks old, male, } \\
350-375 \mathrm{~g} \text { ) } \\
34 \text { rats, } 34 \text { teeth } \\
\text { (split-mouth design } \\
\text { treated vs. untreated teeth) }\end{array}$ & $\begin{array}{l}\text { Upper molars } \\
\text { Healthy pulp }\end{array}$ & $\begin{array}{l}1 \% \mathrm{NaOCl}, 17 \% \text { EDTA, } \\
\text { widening of } \\
\text { apical foramen }\end{array}$ & $\begin{array}{ll}\text { - } & \text { (A) chitosan scaffold (B) } \\
\text { chitosan scaffold + BPMT (C) } \\
\text { evoked bleeding + chitosan } \\
\text { scaffold (D) evoked bleeding + } \\
\text { chitosan scaffold + PBMT } \\
\text { - } \quad 5 \mu \text { of chitosan } \\
\text { - } \quad \text { Temporary filling material + } \\
\text { composite resin } \\
\quad 4 \text { weeks }\end{array}$ & $\begin{array}{l}\text { Histology (HE) } \\
\text { IHC (HSP-25) }\end{array}$ & $\begin{array}{l}\text { - A and B: poor-developed tissue } \\
\text { formation } \\
\text { C: avascular tissue formation } \\
\text { D: well-developed pulp-like tissue } \\
\text { with predentin present along the root } \\
\text { canal walls, newly formed vessels, and } \\
\text { HSP- } 25^{+} \text {cells in contact with predentin }\end{array}$ \\
\hline Siddiqui [26] & $\begin{array}{c}\text { Beagle dogs } \\
\text { (22-26 months old, male) } \\
2 \text { dogs, } 12 \text { teeth } \\
\text { (split-mouth design) }\end{array}$ & $\begin{array}{l}\text { Incisors } \\
\text { Healthy pulp }\end{array}$ & $\begin{array}{l}5.25 \% \mathrm{NaOCl}, 17 \% \mathrm{EDTA}, \\
\mathrm{PBS} \text {, widening of apical } \\
\text { foramen, evoked bleeding }\end{array}$ & $\begin{array}{ll}\text { - } & \text { Self-assembling angiogenic } \\
\text { peptide in hydrogel (SLan), } \\
\text { self-assembling dentinogenic } \\
\text { peptide in hydrogel (SLed), (A) } \\
\text { SLan (B) Sled (C) SLan + SLed } \\
\text { (1:1) (D) PBS } \\
\text { - } \quad \text { Po-25 } \mu \text { Lof hydrogels } \\
\quad \quad \text { Composite resin } \\
4 \text { weeks }\end{array}$ & $\begin{array}{c}\text { Histology } \\
\text { (HE, MT) } \\
\text { IHC (DSP, S100, PECAM) }\end{array}$ & $\begin{array}{l}\text { B and D: poor disorganized tissue } \\
\text { A and C: organized soft tissue with } \\
\text { collagen deposition, large vessels, } \\
\text { nerve bundles, odontoblast-like layer } \\
\text { in the intracanal dentin, and } \mathrm{DPS}^{+} \text {cells }\end{array}$ \\
\hline Torabinejad [27] & $\begin{array}{c}\text { Ferrets } \\
\text { (70 days old, male) } \\
6 \text { Ferrets, } 24 \text { teeth }\end{array}$ & $\begin{array}{l}\text { Immature canines } \\
\text { Apical periodontitis induction } \\
\text { for } 3 \text { weeks }\end{array}$ & $\begin{array}{l}\text { (1) } 1 \% \mathrm{NaOCl} \text {, TAP, sterile } \\
\text { saline, temporary filling } \\
\text { for } 3 \text { weeks } \\
\text { (2) sterile saline, } 17 \% \\
\text { EDTA, Emdogain }\end{array}$ & $\begin{array}{ll}\text { - } & \text { (A) blood clot/Gelfoam (B) PRP } \\
\text { (C) no scaffold } \\
\text { (D) untouched teeth } \\
\text { Commercial products } \\
\text { - } \\
\text { MTA + GIC } \\
\text { 3 months }\end{array}$ & Histology (HE) & $\begin{array}{l}\text { - A and B: apical narrowing and hard } \\
\text { tissue deposition similar to each other } \\
\text { and increased compared to group } C \\
\text { In } 2 / 6 \text { teeth of group } A, 3 / 6 \text { teeth of } B \text {, } \\
\text { and } 1 / 4 \text { teeth of group C: bone- or } \\
\text { cementum-like tissue ingrowth mixed } \\
\text { with connective tissues in the } \\
\text { apical third } \\
\text { All groups: no root lengthening at any } \\
\text { sample. Resolution of the periapical } \\
\text { lesions in all groups except group C }\end{array}$ \\
\hline
\end{tabular}


Table 2. Cont.

\begin{tabular}{|c|c|c|c|c|c|c|}
\hline Author & $\begin{array}{c}\text { Animal/ } \\
\text { Sample Size }\end{array}$ & $\begin{array}{l}\text { Tooth Type/ } \\
\text { Pulp State }\end{array}$ & $\begin{array}{c}\text { Chemomechanical Canal } \\
\text { Preparation }\end{array}$ & $\begin{array}{c}\text { Signaling Molecules, Groups/ } \\
\text { Concentrations/ } \\
\text { Restorative Material/ } \\
\text { Duration of Treatment }\end{array}$ & $\begin{array}{l}\text { Evaluation } \\
\text { Methodology }\end{array}$ & Main Results \\
\hline $\mathrm{He}[28]$ & $\begin{array}{l}\text { Micro-Yucatan minipigs } \\
\text { (24 months old, } \\
110-120 \mathrm{~kg}) \\
10 \text { pigs, } 58 \text { teeth }\end{array}$ & $\begin{array}{l}\text { Mandibular } \\
\text { incisors } \\
\text { Healthy }\end{array}$ & Sterile saline & $\begin{array}{ll}\text { - } & \text { (A) rhWnt3a (B) BMP7 (C) } \\
\text { rhWnt3a + BMP7 (all in collagen } \\
\text { gel) (D) only collagen gel } \\
\text { - } \quad 50 \mathrm{ng} / \mathrm{mL} \text { rhWnt3a, } \\
\quad 1.25 \mathrm{mg} / \mathrm{mL} \text { BMP7 } \\
\text { - } \quad \text { Temporary filling + } \\
\text { composite resin } \\
\text { - } \quad 3 \text { months }\end{array}$ & $\begin{array}{c}\text { Radiographs } \\
\text { Histology (HE, MT) }\end{array}$ & $\begin{array}{l}\text { - A and C: vascularized dental pulp-like } \\
\text { tissue with neural filament-like } \\
\text { structures and mineralized dentin-like } \\
\text { tissue with dentinal tubules and } \\
\text { odontoblast processes in the newly } \\
\text { formed dentin } \\
\text { B: excessive mineralization with } \\
\text { embedded cells resembling bone }\end{array}$ \\
\hline Moradi [29] & $\begin{array}{l}\text { Mixed breed dogs } \\
\text { (6 months old, male) } \\
2 \text { dogs, } 28 \text { teeth }\end{array}$ & $\begin{array}{l}\text { Immature premolars } \\
\text { Induced pulp necrosis for } \\
2 \text { weeks }\end{array}$ & $\begin{array}{l}\text { (1) Normal saline, } 5.25 \% \\
\text { NaOCl, TAP for } 3 \text { weeks } \\
\text { (2) } 5.25 \% \text { NaOCl, saline, } \\
\text { evoked bleeding (BC) }\end{array}$ & $\begin{array}{ll}\text { - } & \text { (A) BC + PRP + MTA (B) BC + } \\
& \text { MTA (C) only induced pulp } \\
& \text { necrosis (D) untouched teeth } \\
\text { - } \quad & \text { GIC } \\
\text { - } & 1 \text { month } \\
& \text { From } 20 \mathrm{~mL} \text { blood }\end{array}$ & $\begin{array}{c}\text { Histology (HE) } \\
\text { IHC } \\
\text { (VEGF \& factor VIII) }\end{array}$ & $\begin{array}{l}\text { - A and B: Newly formed soft connective } \\
\text { tissue, vessels, and hard mineralized } \\
\text { tissue formation. Microvessel density } \\
\text { similar to each other and higher than } \\
\text { Group D. Severe positive expressions } \\
\text { of VEGF and factor VIII which peaked } \\
\text { after } 1 \text { month } \\
\text { - C: no new vital tissue }\end{array}$ \\
\hline
\end{tabular}

* The abbreviations included in Tables 2 and 3 are cumulatively described in the Abbreviations.

Table 3. Ectopic animal studies *. The studied signaling biomolecules are indicated in bold.

\begin{tabular}{|c|c|c|c|c|c|c|}
\hline Author & $\begin{array}{c}\text { Animal/ } \\
\text { Sample Size }\end{array}$ & Tooth Type & $\begin{array}{l}\text { Chemomechanical Canal } \\
\text { Preparation/ } \\
\text { Pulpitis Induction }\end{array}$ & $\begin{array}{c}\text { Signaling Molecules, Groups/ } \\
\text { Concentrations/ } \\
\text { Restorative Material/ } \\
\text { Duration of Treatment }\end{array}$ & $\begin{array}{l}\text { Evaluation } \\
\text { Methodology }\end{array}$ & Main Results \\
\hline $\operatorname{Li}[30]$ & $\begin{array}{c}\text { Haarlan mice } \\
\text { (5 weeks old, } \\
\text { subcutaneously, dorsum) } \\
12 \text { mice, } 6 \text { samples/group }\end{array}$ & $13 \mathrm{~mm}$ human teeth roots & $\begin{array}{l}\text { Widening to } 1 \mathrm{~mm} \text { of the } \\
\text { apical foramen, } 17 \% \text { EDTA } \\
\text { for } 10^{\prime}, 19 \% \text { citric acid for } \\
11^{\prime}, \text { Betadine for } 30^{\prime}, \text { and } \\
5.25 \% \text { NaOCl for } 1^{\prime}, \text { PBS, } \\
\text { incubation for } 3-7 \text { days }\end{array}$ & $\begin{array}{ll}\text { - } & \text { (A) empty (B) DPSC (C) } \\
\text { VEGF-loaded HG-MS } \\
\text { (Heparin-conjugated gelatin } \\
\text { nanospheres immobilized in } \\
\text { PLLA microspheres) (D) } \\
\text { VEGF-loaded HG-MS + DPSCs } \\
100 \mu g \text { rhVEGF in PBS } \\
\text { containing 0.1\% BSA at a } \\
\text { concentration of } 100 \mu \mathrm{\mu g} / \mathrm{mL} \\
\text { - Coronal end sealed with MTA } \\
\quad 9 \text { weeks }\end{array}$ & $\begin{array}{c}\text { Histology (HE) } \\
\text { IHC (h-mit, DSP, Nestin, CD31 } \\
\text { and vWF) }\end{array}$ & $\begin{array}{l}\text { - A and C: minimal soft tissue formation, } \\
\text { vascularization only at the apical third, } \\
\text { very weak CD31, vWF, DSP, and } \\
\text { Nestin detection } \\
\text { B: pulp-like tissue regenerated } \\
\text { decreased in the middle third, high } \\
\text { expression of Nestin and DSP } \\
\text { D: regenerated pulp-like tissue reached } \\
\text { the coronal third of the canal, } \\
\text { odontoblast-like cells (both cell types of } \\
\text { human DPSC origin), many blood } \\
\text { vessels (endothelial cells of host mouse } \\
\text { origin) and strong vWF, CD31, DSP, } \\
\text { and Nestin detection }\end{array}$ \\
\hline
\end{tabular}


Table 3. Cont.

\begin{tabular}{|c|c|c|c|c|c|c|}
\hline Author & $\begin{array}{c}\text { Animal/ } \\
\text { Sample Size }\end{array}$ & Tooth Type & $\begin{array}{c}\text { Chemomechanical Canal } \\
\text { Preparation/ } \\
\text { Pulpitis Induction }\end{array}$ & $\begin{array}{c}\text { Signaling Molecules, Groups/ } \\
\text { Concentrations/ } \\
\text { Restorative Material/ } \\
\text { Duration of Treatment }\end{array}$ & $\begin{array}{l}\text { Evaluation } \\
\text { Methodology }\end{array}$ & Main Results \\
\hline Kim [31] & $\begin{array}{c}\text { Haarlan mice } \\
\text { (5-7 weeks old, male, } \\
\text { subcutaneously, dorsum) }\end{array}$ & $\begin{array}{l}\text { Human permanent maxillary } \\
\text { and mandibular incisors } \\
\text { and cuspids }\end{array}$ & Autoclaved & $\begin{array}{ll}\text { - } & \text { (A) bFGF (B) bFGF + VEGF2 (C) } \\
\text { VEGF, (D) bFGF + NGF + } \\
\text { BMP7 (E) VEGF2 + NGF + } \\
\text { BMP7 (F) PDGF + NGF + BMP7 } \\
\text { (all in collagen gel) (G) collagen } \\
\text { gel without GFs } \\
\text { 10 ng/mL VEGF2,100 ng/mL b } \\
\text { FGF, } 10 \mathrm{ng} / \mathrm{mL} \text { PDGF, 50 } \\
\text { ng/mL NGF, } 100 \mathrm{ng} / \mathrm{mL} \text { BMP7 } \\
\text { in } 2 \mathrm{mg} / \mathrm{mL} \text { collagen gel } \\
\text { - } \quad 3 \text { restorative material } \\
3 \text { weeks }\end{array}$ & $\begin{array}{c}\text { Histology (HE) } \\
\text { IHC (VEGF) } \\
\text { ELISA (vWF, DSP and NGF) }\end{array}$ & $\begin{array}{ll}\text { - } & \text { A: revascularization with abundant } \\
\text { cells and some ECM } \\
\text { - } \quad \text { and D: recellularization in the entire } \\
\text { canal with blood vessel-like structures } \\
\text { - } \quad \text { C: vascularization and connective } \\
\text { tissue with abundant cells } \\
\text { - } \quad \text { E: recellularization and amorphous } \\
\text { dentin-like tissue layer on the native } \\
\text { dentinal wall with multiple blood } \\
\text { vessel-like structures } \\
\text { F: recellularization along the entire } \\
\text { canal with blood vessel-like structures } \\
\text { and some ECM } \\
\text { G: residual of scaffold but little } \\
\text { cell ingrowth }\end{array}$ \\
\hline Takeuchi [32] & $\begin{array}{c}\text { SCID mice } \\
\text { (5 weeks old, } \\
\text { subcutaneously) }\end{array}$ & $6 \mathrm{~mm}$ porcine 2 nd incisor roots & $\begin{array}{l}\text { Widening to } 1 \mathrm{~mm} \text { of } \\
\text { apical foramen }\end{array}$ & $\begin{array}{ll}\text { - } & \text { (A) bFGF (B) G-CSF (C) } \\
\text { - } & 15 \mu \mathrm{g} / \mathrm{mL} \text { (D) only collagen } \\
\text { G-CSF, } 15 \mu \mathrm{g} / \mathrm{mL} \\
\text { - } \quad \text { Zinc phosphate } \\
\text { cement coronally } \\
\text { - } \quad 21 \text { days }\end{array}$ & $\begin{array}{c}\text { Histology (HE) } \\
\text { IHC } \\
\text { TRH-DE (enamelysin, DSPP) }\end{array}$ & $\begin{array}{l}\text { A and B: Similarly regenerated pulp } \\
\text { tissue, cell density, newly formed } \\
\text { capillaries, enamelysin- and } \\
\text { DSPP-positive cells, and TRH-DE but } \\
\text { less than Group C }\end{array}$ \\
\hline Yadlapati [33] & $\begin{array}{l}\text { C57BL/6 mice } \\
\text { (subcutaneously, } \\
\text { dorsum, female) } \\
5 \text { mice, } 10 \text { teeth } \\
\text { (split animal design } \\
\text { right:left side/VF:Control) }\end{array}$ & $10 \mathrm{~mm}$ human premolar roots & $\begin{array}{l}\text { Widening to } 1 \mathrm{~mm} \text { of } \\
\text { apical foramen, } \\
1.5 \% \mathrm{NaOCl}, 17 \% \text { EDTA }\end{array}$ & $\begin{array}{l}\text { - } \quad \text { VEGF in polydioxanone fibers } \\
\text { (VF), (A) Human root fragments } \\
\text { with VF (B) empty roots } \\
12.2 \mathrm{ng} / \mathrm{cm} \text { in } \\
\text { - } \\
\text { - } \quad \text { MTAdioxanone fibers } \\
\text { - } \quad 45 \text { days }\end{array}$ & Histology (HE) & $\begin{array}{l}\text { A: new blood vessels and connective } \\
\text { tissue in root canal at } 45 \text { days } \\
\text { B: no new blood vessels or } \\
\text { connective tissue }\end{array}$ \\
\hline Galler [34] & $\begin{array}{l}\text { Mice } \\
\text { (8-10 weeks old, } \\
\text { subcutaneously } \\
\text { dorsum, female) } \\
\quad 40 \text { teeth }\end{array}$ & $\begin{array}{l}\text { Dentin cylinders from coronal } \\
\text { parts of human molars }\end{array}$ & $5 \% \mathrm{NaOCl}, 17 \%$ EDTA & $\begin{array}{ll}\text { - } & \text { bFGF, TGF- } \beta 1 \text {, and VEGF in } \\
\text { hydrogel from self-assembling } \\
\text { multi-domain peptides (MDPs), } \\
\text { (A) MDP, No GF, No cells (B) } \\
\text { MDP, GF, No cells (C) MDP, No } \\
\quad \text { GF, cells D) MDP, GF, cells } \\
\text { 100 ng TGF- } \beta 1,400 \text { ng FGF2, } \\
\text { and } 100 \text { ng } / 100 \mu \mathrm{L} \text { gel, } \\
\quad 2 \times 10^{6} \text { DPSCs } \\
\quad \text { No restorative material } \\
\quad 5 \text { weeks }\end{array}$ & $\begin{array}{c}\text { Histology } \\
\text { (HE, MT) } \\
\text { IHC (DSP, factor VIII) }\end{array}$ & $\begin{array}{l}\text { - A: only the MDP present and cylinder } \\
\text { enclosed in fibrous capsule } \\
\text { B: filled with soft connective tissue } \\
\text { C: not enough cells to fill the cylinder } \\
\text { and degrade the matrix, no } \\
\text { tissue observed } \\
\text { D: vascularized dental pulp-like soft } \\
\text { connective tissue, collagenous ECM, } \\
\text { cells in contact with dentin wall and } \\
\text { cellular processes into the tubules } \\
\text { expressing DSP, micro vessels, and } \\
\text { endothelial factor VIII }\end{array}$ \\
\hline
\end{tabular}


Table 3. Cont.

\begin{tabular}{|c|c|c|c|c|c|c|}
\hline Author & $\begin{array}{c}\text { Animal/ } \\
\text { Sample Size }\end{array}$ & Tooth Type & $\begin{array}{c}\text { Chemomechanical Canal } \\
\text { Preparation/ } \\
\text { Pulpitis Induction }\end{array}$ & $\begin{array}{l}\text { Signaling Molecules, Groups/ } \\
\text { Concentrations/ } \\
\text { Restorative Material/ } \\
\text { Duration of Treatment }\end{array}$ & $\begin{array}{l}\text { Evaluation } \\
\text { Methodology }\end{array}$ & Main Results \\
\hline Suzuki [35] & $\begin{array}{c}\text { Rats } \\
\text { (5-7 weeks old, } \\
\text { subcutaneously dorsum) } \\
4 \text { samples }\end{array}$ & Human teeth & PBS, Autoclaved & $\begin{array}{ll}\text { - } & \text { (A) bFGF in collagen gel (B) } \\
\text { only collagen gel } \\
100 \mathrm{ng} / \mathrm{mL} \text { bFGF in } 2 \mathrm{mg} / \mathrm{mL} \\
\text { collagen gel } \\
\text { - No restorative material } \\
\quad 3 \text { weeks }\end{array}$ & Histology & $\begin{array}{l}\text { A: Red pigmentation, recellularization } \\
\text { and tissue integration compared to } \\
\text { collagen gel group which appeared } \\
\text { pale with residual collagen scaffold }\end{array}$ \\
\hline Prescott [36] & $\begin{array}{l}\text { Mice } \\
\text { (subcutaneously, } \\
\text { dorsum, } 27 \mathrm{~g} \text { ) } \\
20 \text { teeth }\end{array}$ & $\begin{array}{l}\text { Dentin cylinders from human } \\
\text { 3rd molars }\end{array}$ & Autoclaved & $\begin{array}{l}\text { DMP1 in collagen scaffold, (A) } \\
\text { MTA (B) Collagen scaffold (C) } \\
\text { Collagen scaffold + DMP1 (D) } \\
\text { Collagen scaffold + DPSCs + } \\
\text { DMP1 (E) Collagen } \\
\text { scaffold + DPSCs } \\
\quad 1.2 \mathrm{mg} / \mathrm{mL} \text { in } 100 \mu \mathrm{L} \text { collagen, } \\
\quad 5 \times 10^{6} \text { DPSCs } \\
\text { No restorative material } \\
6 \text { weeks }\end{array}$ & $\begin{array}{l}\text { Histology } \\
\text { (HE, Safranin-O, von } \\
\text { Kossa, MT) }\end{array}$ & $\begin{array}{l}\text { A: few red blood cells } \\
\text { B: degrading scaffold but not replaced } \\
\text { by tissue, few red blood cells, and } \\
\text { nucleated cells } \\
\text { C: Large numbers of viable cells, some } \\
\text { collagen matrix formation but not in } \\
\text { the central perforation site, degrading } \\
\text { collagen scaffold } \\
\text { D: Degrading collagen scaffold, } \\
\text { fibroblasts and endothelial cells, blood } \\
\text { vessels and new collagen } \\
\text { matrix formation } \\
\text { E: similar to group B, some red blood } \\
\text { and nucleated cells, degrading scaffold, } \\
\text { no new matrix nor cells }\end{array}$ \\
\hline Ruangsawasdi [37] & $\begin{array}{l}\text { Sprague Dawley rats } \\
\text { (adult, calvariae, female, } \\
200-250 \mathrm{~g}) \\
20 \text { teeth (split } \\
\text { mouth design) }\end{array}$ & Human immature premolars & $5 \% \mathrm{NaOCl}, 17 \%$ EDTA & $\begin{array}{ll}\text { - } & \text { (A) SCF in fibrin gels (B) only } \\
\text { - fibrin hydrogel } \\
\text { - } 15 \mu \mathrm{m} / \mathrm{mL} \mathrm{SCF} \\
\text { GIC } \\
6 \& 12 \text { weeks }\end{array}$ & $\begin{array}{c}\text { Histology } \\
\text { (Goldner's trichrome) } \\
\text { qPCR (DMP1, DSPP, Col1, NGF, } \\
\text { and VEGF) }\end{array}$ & $\begin{array}{l}\text { A: increased extent of tissue ingrowth, } \\
\text { early blood vessel, and immature } \\
\text { mineral matrix formation at } 6 \text { weeks } \\
\text { compared to the control. At } 12 \text { weeks } \\
\text { the tissue ingrowth was not significant } \\
\text { anymore, but the tissue was more } \\
\text { mature. Hard tissue at the apical } \\
\text { opening, improved revascularization, } \\
\text { and odontoblast-like processes further } \\
\text { down the dentinal tubules. } \\
\text { Upregulation of DMP1, Col1, } \\
\text { and VEGF }\end{array}$ \\
\hline
\end{tabular}

* The abbreviations included in Tables 2 and 3 are cumulatively described in the Abbreviations. 
In 5 out of 10 orthotopic studies, pulpitis/pulp necrosis was induced before the treatment. Sodium hypochlorite $(\mathrm{NaOCl})$, at a range of concentrations, was chosen in 9 out of 10 orthotopic (from 0.5 to $5.25 \%$ ) and in 4 out of 8 ectopic studies (1.5 to $5.25 \%$ ) to disinfect the root canals. Teeth were autoclaved in 3 out of 8 ectopic studies. For further disinfection, smear layer removal and demineralization of the intracanal dentin, EDTA 17\% was used in 6 orthotopic and 4 ectopic studies. EDTA was either washed off or used as the final step of the chemo-mechanical preparation of the roots. In 5 out of 10 orthotopic studies, mature (closed apex) teeth were used, while in the rest immature (open apex) teeth were used. In all orthotopic cases, where an induced pulp infection was established, triple antibiotic paste (TAP) was applied in the root canals between the sessions, until the final stage of regenerative endodontic procedure was performed. In order to accommodate an easier recruitment of the extracanal cells into the root canal, the dental apical foramen was widened by mechanical means, e.g., $\mathrm{K}$ files in $40 \%$ of the orthotopic and in $25 \%$ of the ectopic studies. In ectopic studies, mostly decoronized teeth/roots or dentin cylinders were transplanted, with sealed or non-sealed coronal opening. The most common (60\%) sealing material of the orthotopic studies was mineral trioxide aggregate (MTA), followed by glass ionomer cement (GIC) (20\%) and composite resin (20\%). The duration of orthotopic treatment ranged from 1 to 4 months, while ectopic studies lasted from 3 to 12 weeks. The endpoints of the treatment were evaluated in all studies by histology, followed by immunohistochemistry (IHC), radiographs, and in few by Polymerase Chain Reaction (PCR) analysis.

Regarding the signaling molecules that were applied for the complete dentin/pulp regeneration, bFGF and VEGF were each applied in 5 studies, BMP7 and Platelet-Rich Plasma (PRP) in 3 studies, and PDGF and NGF in 2 studies. TGF-b1, Dentin Matrix Protein-1 (DMP1), Concentrated GF (CGF), SDF-1a, Stem Cell Factor (SCF), dental pulp extracellular matrix (DP-ECM), chitosan, self-assembling peptides (SAPs), Wnt signaling protein 3a (Wnt3a), and Granulocyte-Colony Stimulating Factor (G-CSF) were each used in 1 study. One orthotopic and four ectopic studies included stem cell transplantation; these studies compared the cell-free approach to a cell-based model. Therefore, these studies were included since the cell transplantation was not evaluated as the main tissue engineering factor.

The clinical, radiographical and histological outcome measures of the studies included: healing of periapical lesions (when pulp infection was previously induced); root development and apical closure (when immature teeth were evaluated); cellular recolonization of the pulp space; ingrowth of pulp-like connective tissue; vascularization and innervation in the pulp space; mineralized dentin-like tissue formation along the internal dentin walls; and odontoblast-like cells in contact with the internal dentin walls. More information on the results of the included studies can be seen in Tables 2 and 3. In some cases, bone- and cementum-like tissue, as well as fibrodentin, were observed.

\subsection{Risk of Bias Assessment}

The risk of bias assessment of the included studies is depicted in Figure 2. The studies scored moderately on the selection bias component, where most of the studies stated 'samples/animals were randomly divided into groups', without providing information about the randomization process. Only one study provided information about controlled housing and two about same housing conditions among groups. Performance and detection blinding was rarely stated, while only a few studies reported the number of samples that were eventually assessed along with the missing values. No design-specific risk was observed among the studies. 


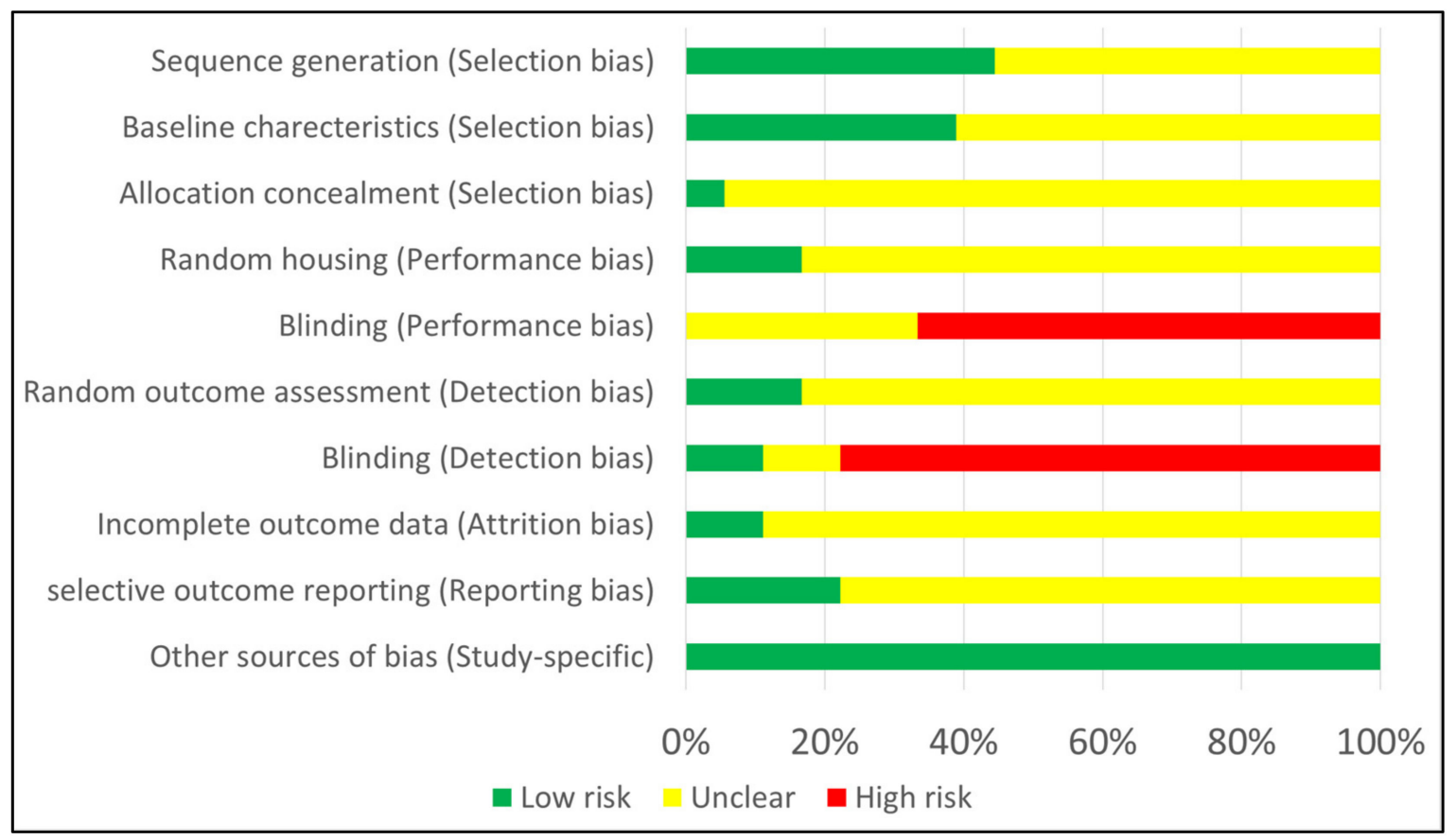

Figure 2. Risk of bias using SYRCLE's tool for animal studies.

\section{Discussion}

Conservative dentistry treats irreversible pulpitis and pulp necrosis by replacing the defected pulp tissue with root canal-filling materials e.g., gutta-percha. Pulp replacement by inert biomaterials is bound to multiple limitations, the most prevalent being tooth sensation loss and tooth brittleness, which results in vulnerability to fractures. The goal of TE approaches is for defected tissues to be regenerated and not to be replaced permanently by inert biomaterials. To this end, stem cells, scaffolds, and stimulating factors, including signaling molecules, are proposed in the context of a regenerative approach [38].

The initial discovery of DPSCs by Gronthos et al. in 2000, along with the later discovery of SHEDs and SCAPs, led to an increased research interest around dentin/pulp tissue regeneration, with many in vitro studies already published [39-41]. Due to their origin, these cells have the ability to differentiate into odontoblasts and neural and endothelial cells [42]. The two main approaches of dentin-pulp complex regeneration include cell-based and cell-free techniques. In cell-based techniques, exogenous, autologous, or allogeneic stem cells are collected, processed in vitro, and later transplanted into the area of interest [43]. In cell-free approaches, endogenous stem cells-that often reside in perivascular niches - are chemotactically activated, recruited to the area of interest, and differentiated into the relevant cell types [44]. Even though many cell-based studies in animals, and few recently published in humans, have shown promising results in dentin-pulp regeneration, the potential risks and handling as well as the cost-related limitations of stem cell therapies, have led to a proposed shift towards the cell-free approach [45-47].

Dentin and pulp regeneration are complex and highly organized by signaling molecules. Our study evaluated the advantageous effect of additionally applied signaling molecules to dentin-pulp complete regeneration in animal studies. Fully pulpectomized teeth, roots, and dentin cylinders in orthotopic or ectopic animal models were evaluated; studies on partial regeneration (pulp capping or partial pulpotomy) were excluded.

Several signaling molecules have been proposed to support this concept, including FGF2, PDGF, VEGF, NGF, TGFb1, SDF1, BMP2/4/7/11, and IGF. Among those, Fibroblast growth factors (FGF) form a family of 22 polypeptides, of which bFGF is the most frequently investigated in dentin/pulp regeneration. BFGF is involved in all stages of pulp repair/regeneration and uses multiple signaling pathways to control the relevant biological 
procedures [48]. BFGF binds to tyrosine kinase FGF receptors $1-4$ on the cell membrane, and phosphorylation occurs. Then, a cascade of intracellular signaling pathways, such as the RAS-MAPK, PI3K-AKT, PLC $\gamma$, and JAK/STAT, initiate cell migration, proliferation, and differentiation [49]. Five included studies used bFGF alone or in combination with other signaling molecules for pulp regeneration [22,31,32,34,35]. Suzuki et al. transplanted ectopically human teeth treated with bFGF in collagen gel subcutaneously in the dorsum of rats for 3 weeks. Histological assessment revealed red pigmentation, recellularization, and tissue integration compared to the negative control group [35]. Takeuchi et al. transplanted porcine roots, treated with bFGF or G-CSF in collagen, subcutaneously in mice for 21 days, resulting in similar regeneration of pulp-like tissue, intracanal cell density, and newly formed capillaries [32]. G-CSF is a chemotactic molecule already approved by the Food and Drug Administration (FDA) for clinical use. G-CSF has been found to mobilize the migration of DPSCs of high stemness, the proliferation, and the differentiation of endogenous stem cells; to enhance vascularization and innervation; and to present anti-inflammatory and anti-apoptotic properties [50].

VEGF is characterized as an important factor with pro-angiogenic activity having a mitogenic and anti-apoptotic effect on endothelial cells and enhancing cell migration and high vascular permeability [51]. VEGFs form a family of several growth factors, namely VEGF-A, -B, -C, -D, -E, -F, -PIGF, and IG-VEGF. These factors bind to tyrosine kinase cell receptors, VEGFRs like VEGFR-1, VEGFR-2, and VEGFR-3. VEGF stimulates vascularization by activating multiple signaling pathways. VEGF-A binding on VEGF-R2 on plasma membrane of endothelial cells leads to downstream signaling of the PLC $\gamma /$ PKC causing cell proliferation; of PI3K enhancing cell survival and vasodilatation permeability; and of MAPK causing cell migration [51]. Five included studies investigated the role of VEGF (VEGF-A and -C) alone or in combination with other signaling molecules in dentin/pulp regeneration [22,30,31,33,34]. Li et al. transplanted full-length human roots treated with VEGF-loaded heparin-conjugated gelatin nanospheres immobilized in PLLA microspheres (HG-MS) subcutaneously in mice for 9 weeks. The results showed minimal soft tissue formation, but to a lesser extent compared to DPSCs transplantation along with VEGF [30]. Yadlapati et al. transplanted human roots treated with VEGF-A in polydioxanone fibers subcutaneously in mice, resulting in new blood vessels and connective tissue formation at 45 days [33].

BMPs constitute a family of proteins with a major role in tooth development, initiation, morphogenesis, cytodifferentiation, and matrix secretion acting through complex signaling networks [52]. BMP signaling pathway is regulated by intracellular domains, membrane sites or extracellular sites. Through two transmembrane receptors, type I and type II, with serine-threonine kinase activity expressed in dental pulp, BMP signals are transferred to the nucleus by Smad proteins, receptor-activated Smads (R-Smads), common mediator Smads (co-Smads), and inhibitory Smads (I-Smads). Three included studies evaluated the role of BMP7 alone or in combination with other signaling molecules [22,28,31]. He et al. treated minipig teeth with BMP7 in collagen gel for 3 months, resulting in excessive mineralization with embedded cells resembling bone. Though, when BMP7 was combined with Wnt3a application, vascularized dental pulp-like tissue and mineralized dentin-like tissue with dentinal tubules and neural filament-like structures were observed [28]. The Wnt family, consisting of 19 cysteine-rich glycoprotein members, is important in regulating cellular functions, self-renewal, proliferation, differentiation, and motility. Wnt signaling is a fundamental signaling in dentin/pulp regeneration controlling cell proliferation, differentiation, polarization, and apoptosis. Wnt3a acts through the canonical Wnt signaling pathway where Wnt3a binds to its receptor Frizzled (Fz) and co-receptor lipoprotein receptor-related protein (LRP5/6), and then Disheveled (Dvl) protein is activated. The complex of casein kinase 1 (CK1), glycogen synthase kinase- $3 \beta($ GSK- $3 \beta$ ) and the adenomatous polyposis coli (APC) proteins, Axin1 and Axin2, are dissociated leading to $\beta$-catenin degradation. The transportation of $\beta$-catenin into the nucleus regulates the expression of Wnt genes [53]. 
NGF is the most frequently investigated neurotrophic factor that promotes neuritis outgrowth in vivo and in vitro [54]. NGF binds to the specific receptor tropomyosin kinase receptor A (TrkA) activating the signaling pathways of MAPK, ERK, PI3K, PLC, and to the non-selective P75 pan-neurotrophin receptor ( $p 75^{\mathrm{NTR}}$ ) activating Jun kinase signaling cascade, NF- $\mathrm{kB}$ and ceramide generation [55]. PDGF signaling contains four ligands, PDGFA-D and two tyrosine kinase receptors, PDGFR- $\alpha$, and $-\beta$. PDGF-BB has been found to act as a chemoattractant by activating the PI3K/Akt signaling pathway to enhance DPSC proliferation, angiogenesis, and odontogenic differentiation, while having the ability to induce cell homing and support dentin-pulp complex regeneration in vivo [56]. Two included studies evaluated the combined use of NGF and PDGF with other signaling molecules in dentin/pulp regeneration [22,31]. El Ashiry et al. treated immature human apical pulpitis-induced teeth with VEGF, bFGF, VEGF, PDGF, NGF, and BMP7 in chitosan hydrogels for four months, while Kim et al. transplanted human teeth treated with the same combination of factors subcutaneously in mice for three weeks [22,31]. In the first study, periapical lesions were healed, radicular thickening, root lengthening, and apical closure were observed, but no dentin/pulp-like tissue was formed. The second study observed recellularization along the entire root canal, blood vessel-like structure, and some ECM formation.

The following signaling molecules were used only in one included study each: CGF, TGF- $\beta 1$, DMP1, and SCF $[20,34,36,37]$. TGF- $\beta 1$ supports cell proliferation and collagen production. TGF- $\beta 1$ induces odontogenic differentiation by activating the ALK $5 / \mathrm{Smad} 2 / 3$, TAK1, p38, and MEK/ERK signaling pathways [57]. Galler et al. transplanted human dentin cylinders treated with TGF- $\beta 1$ in combination with bFGF and VEGF in hydrogels of self-assembling multi-domain peptides (MDPs) subcutaneously in mice for 5 weeks [34]. The results indicated the formation of soft connective tissue. DMP1 is one of the dentin noncollagenous ECM proteins that has been found to regulate mineralization. DMP1 induces odontogenic differentiation and reparative dentin formation in vivo [58]. Prescott et al. transplanted human dentin cylinders treated with DMP1 in collagen scaffolds subcutaneously in mice for 6 weeks, resulting in large numbers of viable cells recruitment and collagen matrix formation in the periphery of the perforation site [36]. SCF is a chemotactic glycoprotein with the ability to recruit stem cells. It enhances cell adhesion, proliferation, migration, and angiogenesis in vitro [59]. Ruangsawasdi et al. transplanted human immature teeth treated with SCF in fibrin gels in rats for 6 and 12 weeks, displaying increased extent of tissue ingrowth, early blood vessel and immature mineral matrix formation at 6 weeks [37]. At 12 weeks, the tissue ingrowth was not significant compared to the control, but the formed tissue was more mature; hard tissue formation at the apical opening, improved revascularization and odontoblast-like processes developed into the dentinal tubules. SDF- $1 \alpha$ is a chemotactic factor widely expressed during dental pulp inflammation. It has been shown that SDF-1/CXCR4 induces stem cell migration by activating FAK/PI3K/Akt and GSK3 $\beta / \beta$-catenin pathways [60]. Yang et al. treated human mature apical periodontitis-induced teeth with SDF-1 $\alpha$ in silk fibroin scaffolds subcutaneously in mice, demonstrating regenerated pulp-like connective tissue of low to moderate density with blood vessel formation, and thin layer of mineralized tissue along the intracanal dentinal walls [21].

Regarding clinical practice, the most recent guidelines of the European Society of Endodontology (ESE) suggest that Regenerative Endodontic Procedures (REP) should be performed in necrotic immature teeth by evoked blood clot formation into the root canals [61]. The ultimate goal of REP would be to achieve a complete regeneration of the dentin-pulp complex and pulp tissue defects, in necrotic immature and mature teeth [17]. This systematic review provides sufficient evidence for the potential of a complete pulp regeneration with the aid of signaling biomolecules following a cell homing-based approach. (Figure 3). Initially, the root canals are chemo-mechanically prepared and disinfected. The apical foramen is widened, and bleeding is evoked, while an injectable scaffold carrying a specific subset of signaling molecules is implanted. These signaling molecules could 
enhance the regeneration of the target tissue. From the included studies, a variety of signaling molecules indicate the supportive role in dentin-pulp complex and pulp tissue regeneration. Further studies should be performed to specify the signaling molecules with the best potential targeted outcome and the best applicable concentration, delivery system, and duration of treatment.

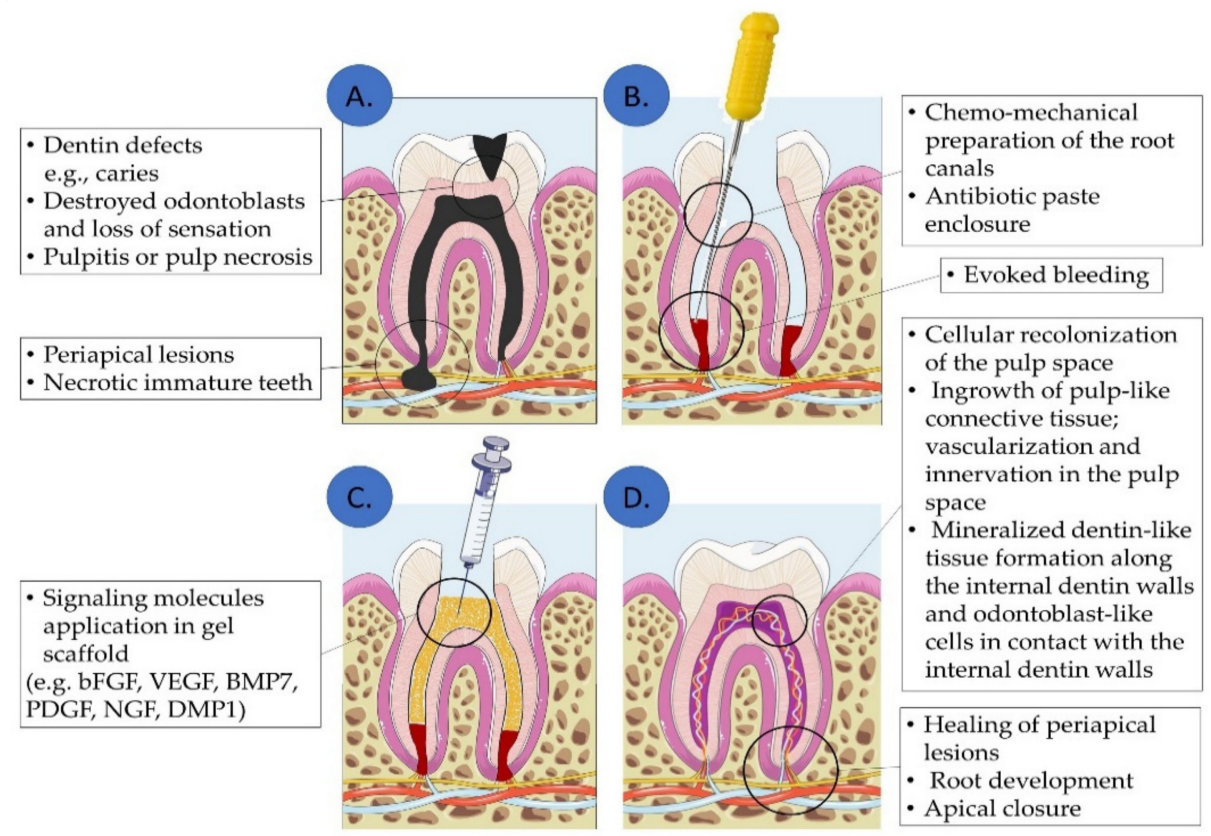

Figure 3. Dentin-pulp complex and pulp tissue regeneration approach by signaling molecules via cell homing: In dentin/pulp defects (A), the pulp chamber is chemomechanically prepared and disinfected and bleeding is evoked (B). Then, signaling biomolecules are applied into the root canals (C), leading to dentin-pulp complex and periapical tissue regeneration (D). (Illustration created using Servier Medical Art at smart.servier.com).

\section{Conclusions}

The included orthotopic and ectopic animal studies indicate that a variety of signaling molecules have the ability to support the complete dentin-pulp complex and pulp tissue regeneration. Vascularization, innervation, intracanal dentin-like formation, or odontoblastlike cell attachment on the intracanal dentinal walls were achieved by multiple molecules and concentrations. Thus, further in vitro studies should be performed to determine a more specific subset combination of molecules for the desired outcome, as well as preclinical and clinical studies. Future research should focus on the clinical application of specific biomolecules, their concentrations, and their exact impact on dentin-pulp complex regeneration. The goal would be to develop a biomolecule-containing 'cocktail' to be applied in dentin or pulp tissues defects and to regenerate natural structure and function in dental clinical practice.

Author Contributions: Conceptualization, A.B. and F.M.; methodology, A.B. and F.M.; writingoriginal draft preparation, A.B. and F.M.; writing-review and editing, I.A., M.E. and M.C.; supervision, A.B.; project administration, A.B. All authors have read and agreed to the published version of the manuscript.

Funding: This research received no external funding.

Institutional Review Board Statement: Not applicable.

Informed Consent Statement: Not applicable.

Acknowledgments: The authors would like to thank Eleftheria Machla for revising the use of English language of the manuscript. 
Conflicts of Interest: The authors declare no conflict of interest.

\section{Abbreviations}

\begin{tabular}{|c|c|}
\hline Abbreviation & Definition \\
\hline Atg5 & Autophagy related 5 \\
\hline $\mathrm{APC}$ & Autologous Platelet Concentrate \\
\hline $\mathrm{BC}$ & Blood Clot \\
\hline BMMSCs & Bone Marrow Mesenchymal Stem Cells \\
\hline $\mathrm{BMP}$ & Bone Morphogenetic Protein \\
\hline BP plus & Root canal sealer (product) \\
\hline BSA & Bovine Serum Albumin \\
\hline CD31 & Cluster of Differentiation 31 \\
\hline Col1 & Collagen type I \\
\hline CGF & Concentrated Growth Factor \\
\hline DMP1 & Dentin Matrix Protein 1 \\
\hline $\mathrm{DP}$ & Dental Pulp \\
\hline $\mathrm{ECM}$ & Extracellular Matrix \\
\hline$(\mathrm{M}) \mathrm{DPSC}$ & (Mobilized) Dental Pulp Stem Cells \\
\hline DSP & Dentin Sialoprotein \\
\hline DSPP & Dentin Sialophosphoprotein \\
\hline EDTA & Ethylenediaminetetraacetic Acid \\
\hline ELISA & Enzyme-linked Immunosorbent Assay \\
\hline $\mathrm{EtOH}$ & Ethanol \\
\hline (b)FGF2 & (basic) Fibroblast Growth Factors 2 \\
\hline G-CSF & Granulocyte Colony-Stimulating Factor \\
\hline GF & Growth Factors \\
\hline GFP & Green Fluorescent Protein \\
\hline GIC & Glass Ionomer Cement \\
\hline $\mathrm{HE}$ & Hematoxylin \& Eosin \\
\hline HG-MS & Heparin-conjugated gelatin nanospheres immobilized in poly-L-lactide microspheres \\
\hline HUVEC & Human Umbilical Vein Endothelial Cell \\
\hline HG & Hydrogel \\
\hline HSP-25 & Human Shock Protein-25 \\
\hline IF & Immunofluorescence \\
\hline IGF & Insulin-like Growth Factor \\
\hline $\mathrm{IHC}$ & Immunohistochemistry \\
\hline IRM & Intermediate Restorative Material (product) \\
\hline LC3 & Microtubule-associated protein 1A/1B-Light Chain 3 \\
\hline MDP & Multi-Domain Peptide \\
\hline MSC & Mesenchymal Stem Cell \\
\hline MT & Masson's Trichrome \\
\hline MTA & Mineral Trioxide Aggregate \\
\hline N.C. & Negative Control \\
\hline $\mathrm{NaOCl}$ & Sodium hypochlorite \\
\hline NGF & Nerve Growth Factor \\
\hline PBMT & Photobiomodulation Therapy \\
\hline PBS & Phosphate Buffer Saline \\
\hline PCNA & Proliferating Cell Nuclear Antigen \\
\hline PDGF & Platelet-Derived Growth Factor \\
\hline PDL & Periodontal Ligament \\
\hline PECAM & Platelet Endothelial Cells Adhesion Molecule \\
\hline PLLA & Poly-L-Lactide \\
\hline $\mathrm{PICO}$ & Population, Intervention, Comparison, Outcome \\
\hline P.C. & Positive Control \\
\hline PRISMA & Preferred Reporting Items for Systematic Reviews and Meta-Analyses \\
\hline PRP & Protein-Rich Plasma \\
\hline (q)PCR & (quantitative) Polymerase Chain Reaction \\
\hline
\end{tabular}




$\begin{array}{ll}\text { rCT } & \text { Regenerated Connective Tissue } \\ \text { REP } & \text { Regenerative Endodontic Procedures } \\ \text { rMT } & \text { Regenerated Mineralized Tissue } \\ \text { SAP } & \text { Self-Assembling Peptide } \\ \text { SCAP } & \text { Stem Cells from the Apical Papilla } \\ \text { SCF } & \text { Stem Cell Factor } \\ \text { SCID } & \text { Severe Combined Immunodeficient } \\ \text { SDF-1a } & \text { Stromal cell-Derived Factor 1a } \\ \text { SHED } & \text { Stem Cells from Human Exfoliated Deciduous Teeth } \\ \text { SLan } & \text { Self-Assembling Angiogenic Peptides } \\ \text { SLed } & \text { Self-Assembling Dentinogenic Peptides } \\ \text { SYRCLE } & \text { Systematic Review Centre for Laboratory Animal Experimentation } \\ \text { TAP } & \text { Triple Antibiotic Paste } \\ \text { TE } & \text { Tissue Engineering } \\ \text { TEM } & \text { Transmission Electron Microscope } \\ \text { TGF-b1 } & \text { Transforming Growth Factor b1 } \\ \text { TRH-DE } & \text { Thyrotropin-Releasing Hormone-Degrading Ectoenzyme } \\ \text { VEGF } & \text { Vascular Endothelial Growth Factor } \\ \text { vWF } & \text { von Willebrand Factor } \\ \text { (rh)Wnt3a } & \text { (Recombinant Human) Wingless Int-1 signaling protein 3a }\end{array}$

\section{References}

1. United Nations General Assembly Political Declaration of the High-Level Meeting of the General Assembly on the Prevention and Control of Non-Communicable Diseases. 2011. Available online: https://digitallibrary.un.org/record/710899 (accessed on 30 December 2021).

2. GBD 2017 Oral Disorders Collaborators Global, Regional, and National Levels and Trends in Burden of Oral Conditions from 1990 to 2017: A Systematic Analysis for the Global Burden of Disease 2017 Study. J. Dent. Res. 2020, 99, 362-373. [CrossRef] [PubMed]

3. Haag, D.G.; Peres, K.G.; Balasubramanian, M.; Brennan, D.S. Oral Conditions and Health-Related Quality of Life: A Systematic Review. J. Dent. Res. 2017, 96, 864-874. [CrossRef] [PubMed]

4. Righolt, A.J.; Jevdjevic, M.; Marcenes, W.; Listl, S. Global-, Regional-, and Country-Level Economic Impacts of Dental Diseases in 2015. J. Dent. Res. 2018, 97, 501-507. [CrossRef] [PubMed]

5. Morimoto, S.; Rebello de Sampaio, F.B.; Braga, N.M.; Sesma, N.; Özcan, M. Survival Rate of Resin and Ceramic Inlays, Onlays, and Overlays: A Systematic Review and Meta-Analysis. J. Dent. Res. 2016, 95, 985-994. [CrossRef] [PubMed]

6. Nanci, A. Dentin-Pulp Complex. Ten Cate's Oral Histol. 2013, 165-204. [CrossRef]

7. Couve, E.; Osorio, R. Schmachtenberg O The Amazing Odontoblast: Activity, Autophagy, and Aging. J. Dent. Res. 2013, 92, 765-772. [CrossRef]

8. Brännström, M. The Hydrodynamic Theory of Dentinal Pain: Sensation in Preparations, Caries, and the Dentinal Crack Syndrome. J. Endod. 1986, 12, 453-457. [CrossRef]

9. Langer, R.; Vacanti, J. Tissue Engineering. Science 1993, 260, 920-926. [CrossRef]

10. Bakopoulou, A. About I Stem Cells of Dental Origin: Current Research Trends and Key Milestones Towards Clinical Application. Stem Cells Int. 2016, 2016, 4209891. [CrossRef]

11. Bakopoulou, A.; Georgopoulou, A.; Grivas, I.; Bekiari, C.; Prymak, O.; Loza, K.; Epple, M.; Papadopoulos, G.C.; Koidis, P.; Chatzinikolaidou, M. Dental Pulp Stem Cells in Chitosan/Gelatin Scaffolds for Enhanced Orofacial Bone Regeneration. Dent. Mater. Off. Publ. Acad. Dent. Mater. 2019, 35, 310-327. [CrossRef]

12. Herberts, C.A.; Kwa, M.S.G.; Hermsen, H.P.H. Risk Factors in the Development of Stem Cell Therapy. J. Transl. Med. 2011, 9, 1-14. [CrossRef] [PubMed]

13. Galler, K.M.; D’Souza, R.N.; Hartgerink, J.D.; Schmalz, G. Scaffolds for Dental Pulp Tissue Engineering. Adv. Dent. Res. 2011, 23, 333-339. [CrossRef]

14. Liu, J.; Yu, F.; Sun, Y.; Jiang, B.; Zhang, W.; Yang, J.; Xu, G.T.; Liang, A.; Liu, S. Concise Reviews: Characteristics and Potential Applications of Human Dental Tissue-Derived Mesenchymal Stem Cells. Stem Cells 2015, 33, 627-638. [CrossRef]

15. Schmalz, G.; Widbiller, M.; Galler, K.M. Signaling Molecules and Pulp Regeneration. J. Endod. 2017, 43, S7-S11. [CrossRef] [PubMed]

16. Kim, S.G.; Zhou, J.; Solomon, C.; Zheng, Y.; Suzuki, T.; Chen, M.; Song, S.; Jiang, N.; Cho, S.; Mao, J.J. Effects of Growth Factors on Dental Stem/ProgenitorCells. Dent. Clin. N. Am. 2012, 56, 563. [CrossRef]

17. Galler, K.M.; Widbiller, M. Perspectives for Cell-Homing Approaches to Engineer Dental Pulp. J. Endod. 2017, 43, S40-S45. [CrossRef] [PubMed]

18. Moher, D.; Liberati, A.; Tetzlaff, J.; Altman, D.G.; Altman, D.; Antes, G.; Atkins, D.; Barbour, V.; Barrowman, N.; Berlin, J.A.; et al. Preferred Reporting Items for Systematic Reviews and Meta-Analyses: The PRISMA Statement. PLoS Med. 2009, 6, 1-7. [CrossRef] 
19. Hooijmans, C.R.; Rovers, M.M.; de Vries, R.B.M.; Leenaars, M.; Ritskes-Hoitinga, M.; Langendam, M.W. SYRCLE's Risk of Bias Tool for Animal Studies. BMC Med. Res. Methodol. 2014, 14, 43. [CrossRef] [PubMed]

20. Xu, F.; Qiao, L.; Zhao, Y.; Chen, W.; Hong, S.; Pan, J.; Jiang, B. The Potential Application of Concentrated Growth Factor in Pulp Regeneration: An in Vitro and in Vivo Study. Stem Cell Res. Ther. 2019, 10, 134. [CrossRef]

21. Yang, J.W.; Zhang, Y.F.; Wan, C.Y.; Sun, Z.Y.; Nie, S.; Jian, S.J.; Zhang, L.; Song, G.T.; Chen, Z. Autophagy in SDF-1 $\alpha$-Mediated DPSC Migration and Pulp Regeneration. Biomaterials 2015, 44, 11-23. [CrossRef]

22. el Ashiry, E.A.; Alamoudi, N.M.; el Ashiry, M.K.; Bastawy, H.A.; el Derwi, D.A.; Atta, H.M. Tissue Engineering of Necrotic Dental Pulp of Immature Teeth with Apical Periodontitis in Dogs: Radiographic and Histological Evaluation. J. Clin. Pediatric Dent. 2018, 42, 373-382. [CrossRef] [PubMed]

23. Alqahtani, Q.; Zaky, S.H.; Patil, A.; Beniash, E.; Ray, H.; Sfeir, C. Decellularized Swine Dental Pulp Tissue for Regenerative Root Canal Therapy. J. Dent. Res. 2018, 97, 1460-1467. [CrossRef]

24. Ghoddusi, J.; Maghsudlu, A.; Jafarzadeh, H.; Jafarian, A.; Forghani, M. Histological Evaluation of the Effect of Platelet-Rich Plasma on Pulp Regeneration in Nonvital Open Apex Teeth: An Animal Study. J. Contemp. Dent. Pract. 2017, 18, 1045-1050. [CrossRef]

25. Moreira, M.S.; Sarra, G.; Carvalho, G.L.; Gonçalves, F.; Caballero-Flores, H.V.; Pedroni, A.C.F.; Lascala, C.A.; Catalani, L.H.; Marques, M.M. Physical and Biological Properties of a Chitosan Hydrogel Scaffold Associated to Photobiomodulation Therapy for Dental Pulp Regeneration: An In Vitro and In Vivo Study. BioMed Res. Int. 2021, 2021, 6684667. [CrossRef] [PubMed]

26. Siddiqui, Z.; Sarkar, B.; Kim, K.K.; Kadincesme, N.; Paul, R.; Kumar, A.; Kobayashi, Y.; Roy, A.; Choudhury, M.; Yang, J.; et al. Angiogenic Hydrogels for Dental Pulp Revascularization. Acta Biomater. 2021, 126, 109-118. [CrossRef] [PubMed]

27. Torabinejad, M.; Milan, M.; Shabahang, S.; Wright, K.R.; Faras, H. Histologic Examination of Teeth with Necrotic Pulps and Periapical Lesions Treated with 2 Scaffolds: An Animal Investigation. J. Endod. 2015, 41, 846-852. [CrossRef]

28. He, L.; Zhou, J.; Chen, M.; Lin, C.S.; Kim, S.G.; Zhou, Y.; Xiang, L.; Xie, M.; Bai, H.; Yao, H.; et al. Parenchymal and Stromal Tissue Regeneration of Tooth Organ by Pivotal Signals Reinstated in Decellularized Matrix. Nat. Mater. 2019, 18, 627-637. [CrossRef]

29. Moradi, S.; Talati, A.; Forghani, M.; Jafarian, A.H.; Naseri, M.; Shojaeian, S. Immunohistological Evaluation of Revascularized Immature Permanent Necrotic Teeth Treated by Platelet-Rich Plasma: An Animal Investigation. Cell J. 2016, 18, 389-396. [CrossRef]

30. Li, X.; Ma, C.; Xie, X.; Sun, H.; Liu, X. Pulp Regeneration in a Full-Length Human Tooth Root Using a Hierarchical Nanofibrous Microsphere System. Acta Biomater. 2016, 35, 57-67. [CrossRef]

31. Kim, J.Y.; Xin, X.; Moioli, E.K.; Chung, J.; Lee, C.H.; Chen, M.; Fu, S.Y.; Koch, P.D.; Mao, J.J. Regeneration of Dental-Pulp-like Tissue by Chemotaxis-Induced Cell Homing. Tissue Eng. Part A 2010, 16, 3023-3031. [CrossRef]

32. Takeuchi, N.; Hayashi, Y.; Murakami, M.; Alvarez, F.J.; Horibe, H.; Iohara, K.; Nakata, K.; Nakamura, H.; Nakashima, M. Similar in Vitro Effects and Pulp Regeneration in Ectopic Tooth Transplantation by Basic Fibroblast Growth Factor and Granulocyte-Colony Stimulating Factor. Oral Dis. 2015, 21, 113-122. [CrossRef] [PubMed]

33. Yadlapati, M.; Biguetti, C.; Cavalla, F.; Nieves, F.; Bessey, C.; Bohluli, P.; Garlet, G.P.; Letra, A.; Fakhouri, W.D.; Silva, R.M. Characterization of a Vascular Endothelial Growth Factor-Loaded Bioresorbable Delivery System for Pulp Regeneration. J. Endod. 2017, 43, 77-83. [CrossRef] [PubMed]

34. Galler, K.M.; Hartgerink, J.D.; Cavender, A.C.; Schmalz, G.; D'Souza, R.N. A Customized Self-Assembling Peptide Hydrogel for Dental Pulp Tissue Engineering. Tissue Eng. Part A 2012, 18, 176-184. [CrossRef]

35. Suzuki, T.; Lee, C.H.; Chen, M.; Zhao, W.; Fu, S.Y.; Qi, J.J.; Chotkowski, G.; Eisig, S.B.; Wong, A.; Mao, J.J. Induced Migration of Dental Pulp Stem Cells for in Vivo Pulp Regeneration. J. Dent. Res. 2011, 90, 1013-1018. [CrossRef] [PubMed]

36. Prescott, R.S.; Alsanea, R.; Fayad, M.I.; Johnson, B.R.; Wenckus, C.S.; Hao, J.; John, A.S.; George, A. In Vivo Generation of Dental Pulp-like Tissue by Using Dental Pulp Stem Cells, a Collagen Scaffold, and Dentin Matrix Protein 1 after Subcutaneous Transplantation in Mice. J. Endod. 2008, 34, 421-426. [CrossRef]

37. Ruangsawasdi, N.; Zehnder, M.; Patcas, R.; Ghayor, C.; Siegenthaler, B.; Gjoksi, B.; Weber, F.E. Effects of Stem Cell Factor on Cell Homing During Functional Pulp Regeneration in Human Immature Teeth. Tissue Eng. Part A 2017, 23, 115-123. [CrossRef]

38. Langer, R.; Vacanti, J. Advances in Tissue Engineering. J. Pediatric Surg. 2016, 51, 8-12. [CrossRef]

39. Gronthos, S.; Mankani, M.; Brahim, J.; Robey, P.G.; Shi, S. Postnatal Human Dental Pulp Stem Cells (DPSCs) in Vitro and in Vivo. Proc. Natl. Acad. Sci. USA 2000, 97, 13625-13630. [CrossRef]

40. Miura, M.; Gronthos, S.; Zhao, M.; Lu, B.; Fisher, L.W.; Robey, P.G.; Shi, S. SHED: Stem Cells from Human Exfoliated Deciduous Teeth. Proc. Natl. Acad. Sci. USA 2003, 100, 5807-5812. [CrossRef]

41. Sonoyama, W.; Liu, Y.; Yamaza, T.; Tuan, R.S.; Wang, S.; Shi, S.; Huang, G.T.J. Characterization of the Apical Papilla and Its Residing Stem Cells from Human Immature Permanent Teeth: A Pilot Study. J. Endod. 2008, 34, 166-171. [CrossRef]

42. Li, B.; Ouchi, T.; Cao, Y.; Zhao, Z.; Men, Y. Dental-Derived Mesenchymal Stem Cells: State of the Art. Front. Cell Dev. Biol. 2021, 9, 1310. [CrossRef] [PubMed]

43. Sui, B.; Chen, C.; Kou, X.; Li, B.; Xuan, K.; Shi, S.; Jin, Y. Pulp Stem Cell-Mediated Functional Pulp Regeneration. J. Dent. Res. 2019, 98, 27-35. [CrossRef] [PubMed]

44. Ahmed, G.M.; Abouauf, E.A.; Abubakr, N.; Fouad, A.M.; Dörfer, C.E.; Fawzy El-Sayed, K.M. Cell-Based Transplantation versus Cell Homing Approaches for Pulp-Dentin Complex Regeneration. Stem Cells Int. 2021, 2021, 8483668. [CrossRef] 
45. Nakashima, M.; Iohara, K.; Murakami, M.; Nakamura, H.; Sato, Y.; Ariji, Y.; Matsushita, K. Pulp Regeneration by Transplantation of Dental Pulp Stem Cells in Pulpitis: A Pilot Clinical Study. Stem Cell Res. Ther. 2017, 8, 61. [CrossRef]

46. Xuan, K.; Li, B.; Guo, H.; Sun, W.; Kou, X.; He, X.; Zhang, Y.; Sun, J.; Liu, A.; Liao, L.; et al. Deciduous Autologous Tooth Stem Cells Regenerate Dental Pulp after Implantation into Injured Teeth. Sci. Transl. Med. 2018, 10, eaaf3227. [CrossRef] [PubMed]

47. Meza, G.; Urrejola, D.; saint Jean, N.; Inostroza, C.; López, V.; Khoury, M.; Brizuela, C. Personalized Cell Therapy for Pulpitis Using Autologous Dental Pulp Stem Cells and Leukocyte Platelet-Rich Fibrin: A Case Report. J. Endod. 2019, 45, 144-149. [CrossRef] [PubMed]

48. Vaseenon, S.; Chattipakorn, N.; Chattipakorn, S.C. The Possible Role of Basic Fibroblast Growth Factor in Dental Pulp. Arch. Oral Biol. 2020, 109, 104574. [CrossRef]

49. Liu, K.; Yu, S.; Ye, L.; Gao, B. The Regenerative Potential of BFGF in Dental Pulp Repair and Regeneration. Front. Pharmacol. 2021, 12, 1677. [CrossRef]

50. Murakami, M.; Horibe, H.; Iohara, K.; Hayashi, Y.; Osako, Y.; Takei, Y.; Nakata, K.; Motoyama, N.; Kurita, K.; Nakashima, M. The Use of Granulocyte-Colony Stimulating Factor Induced Mobilization for Isolation of Dental Pulp Stem Cells with High Regenerative Potential. Biomaterials 2013, 34, 9036-9047. [CrossRef]

51. Stanca Melincovici, C.; Boşca, A.B.; Şuşman, S.; Mărginean, M.; Mihu, C.; Istrate, M.; Moldovan, I.-M.; Roman, A.L.; Mihu, C.M. Vascular Endothelial Growth Factor (VEGF)-Key Factor in Normal and Pathological Angiogenesis. Rom. J. Morphol. Embryol. 2018, 59, 455-467.

52. Nakashima, M. Bone Morphogenetic Proteins in Dentin Regeneration for Potential Use in Endodontic Therapy. Cytokine Growth Factor Rev. 2005, 16, 369-376. [CrossRef] [PubMed]

53. He, S.; Lu, Y.; Liu, X.; Huang, X.; Keller, E.T.; Qian, C.N.; Zhang, J. Wnt3a: Functions and Implications in Cancer. Chin. J. Cancer 2015, 34, 50. [CrossRef] [PubMed]

54. Aloe, L.; Rocco, M.L.; Balzamino, B.O.; Micera, A. Nerve Growth Factor: A Focus on Neuroscience and Therapy. Curr. Neuropharmacol. 2015, 13, 294. [CrossRef] [PubMed]

55. Aloe, L.; Rocco, M.L.; Bianchi, P.; Manni, L. Nerve Growth Factor: From the Early Discoveries to the Potential Clinical Use. J. Transl. Med. 2012, 10, 239. [CrossRef]

56. Zhang, M.; Jiang, F.; Zhang, X.; Wang, S.; Jin, Y.; Zhang, W.; Jiang, X. The Effects of Platelet-Derived Growth Factor-BB on Human Dental Pulp Stem Cells Mediated Dentin-Pulp Complex Regeneration. Stem Cells Transl. Med. 2017, 6, 2126. [CrossRef]

57. Chang, H.H.; Chen, I.L.; Wang, Y.L.; Chang, M.C.; Tsai, Y.L.; Lan, W.C.; Wang, T.M.; Yeung, S.Y.; Jeng, J.H. Regulation of the Regenerative Activity of Dental Pulp Stem Cells from Exfoliated Deciduous Teeth (SHED) of Children by TGF-B1 Is Associated with ALK5/Smad2, TAK1, P38 and MEK/ERK Signaling. Aging 2020, 12, 21253. [CrossRef]

58. Almushayt, A.; Narayanan, K.; Zaki, A.E.; George, A. Dentin Matrix Protein 1 Induces Cytodifferentiation of Dental Pulp Stem Cells into Odontoblasts. Gene Ther. 2006, 13, 611-620. [CrossRef]

59. Mu, X.; Shi, L.; Pan, S.; He, L.; Niu, Y.; Wang, X. A Customized Self-Assembling Peptide Hydrogel-Wrapped Cell Factor Targeting Pulp Regeneration Rich in Vascular-Like. ACS Omega 2020, 5, 16568. [CrossRef]

60. Li, M.; Sun, X.; Ma, L.; Jin, L.; Zhang, W.; Xiao, M.; Yu, Q. SDF-1/CXCR4 Axis Induces Human Dental Pulp Stem Cell Migration through FAK/PI3K/Akt and GSK3 $\beta / \beta$-Catenin Pathways. Sci. Rep. 2017, 7, 40161. [CrossRef]

61. Galler, K.M.; Krastl, G.; Simon, S.; van Gorp, G.; Meschi, N.; Vahedi, B.; Lambrechts, P. European Society of Endodontology Position Statement: Revitalization Procedures. Int. Endod. J. 2016, 49, 717-723. [CrossRef] 